\title{
The Musical Ludo Mix of Taiko no Tatsujin
}

\section{Costantino Oliva}

Transactions of the Digital Games Research Association March 2021, Vol. 5 No 2, pp. 131-160. ISSN 2328-9422

(C) The text of this work is licensed under a Creative Commons Attribution - NonCommercial -NonDerivative 4.0 License (http://creativecommons.org/licenses/by-ncnd/ 2.5/).

IMAGES: All images appearing in this work are property of the respective copyright owners, and are not released into the Creative Commons. The respective owners reserve all rights

\section{ABSTRACT}

This paper analyzes the Taiko no Tatsujin (Bandai Namco 2001/ 2018) franchise and the musical literacy it conveys. While previous accounts of game musical literacy have focused on the competence necessary to interpret references across media (van Elferen 2016), this paper expands on the concept, and includes the discussion of live performances and oral traditions.

The musical compositions included in Taiko no Tatsujin pertain to the Japanese phenomenon of media convergence known as media mix (Steinberg 2012), as they have been previously popularized by anime and geemu ongaku (or game music) (Yamakami and Barbosa 2015). However, the musical participation initiated extends its references to the practice of Japanese taiko drumming, a largely oral, non-notated musical form, which cannot be reduced 
to a musical repertoire. The resulting, emerging ludo mix, a form of media mix centered around digital games (Blom 2019; Bjarnason 2019; Picard and Pelletier-Gagnon 2015; Steinberg 2015), presents original musical characteristics, representing and synthesizing a dynamic musical culture.

The conclusions show that game musical literacy is based, not only on competence with previous media forms, but also with various different forms of participation in musical performances, or musicking (Small 1998), which concur in constructing game musical literacy. The musical side of the ludo mix can therefore be expressed through a large variety of musical practices.

Keywords

Music, Taiko no Tatsujin, media mix, ludo mix, musicking

\section{INTRODUCTION}

Few games have captured the collective imagination about the Japanese arcade scene like the Taiko no Tatsujin franchise. With more than 50 entries, the series has been deployed on platforms such as PS4, Nintendo Switch, PS Vita, Nintendo Wii, Android mobiles and more. Arguably, the most recognizable version of Taiko no Tatsujin remains however its arcade iteration, which features two large drum-shaped input devices. Proportionately large mallets are available to the player, immediately suggesting the option that the drums can be hit hard (Figure 1). 


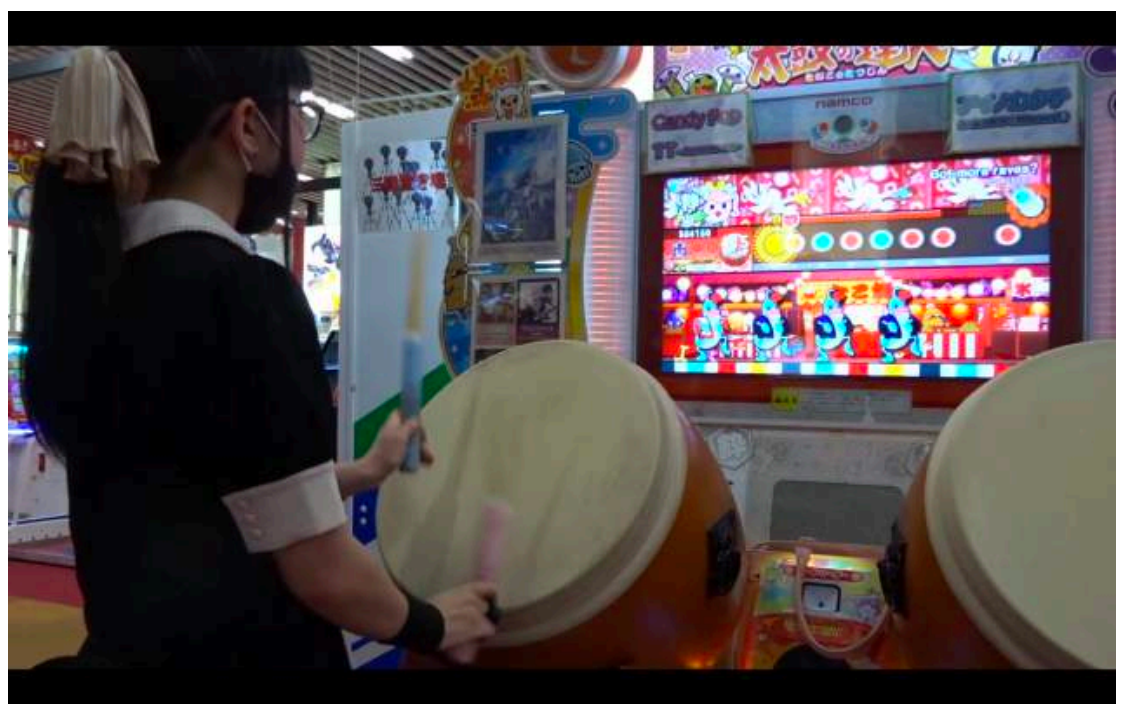

Figure 1: YouTuber, Mikupi, playing an arcade cabinet of Taiko no Tatsujin. Still frame from the YouTube video, "Got more raves?”

The color, shape and general look of the input devices mimic that of a traditional Japanese taiko. The musical compositions included in the game, however, seem to be less based in the actual taiko tradition. In fact, they might be more familiar to fans of digital games, J-pop, or anime. The first game in the series, simply called Taiko no Tatsujin (Namco, 2001), features theme songs related to popular manga and anime characters, such as Doraemon and Ampanman; tracks from other Namco game franchises; and original compositions in diverse genres, from ska to heavy metal. In that regard, Taiko no Tatsujin can be considered as an example of the "ludo mix", "a convergence of products organized around one (or several) central games” (Chiapello 2019). The ludo mix is understood as a game-oriented perspective on the "media mix", or "the practice of marketing interconnected works for different media (manga, anime, movies, etc.) and tie-in products” (Picard and Pelletier-Gagnon 2015) within the context of the Japanese media entertainment industry. While the media mix commonly includes digital games, the concept of ludo mix recognizes that "games increasingly occupy the focal point in the consumption model of the media mix” (Blom 2019). Taiko no Tatsujin, however, 
does not just take part in the media mix by featuring popular characters from anime, but also by including a musical repertoire associated with, and popularized within, the media mix. In that regard, Taiko no Tatsujin heavily relies on the "musical media literacy" of its player, intended as "the fluency in hearing and interpreting film, television or advertising music through the fact of our frequent exposure to them and, subsequently, our ability to interpret their communications” (van Elferen 2016).

The anime songs included in the digital game provide a cultural context situated within the media mix, generating novel ludo mix dynamics, initiating a specific cultural discourse with potential players. This musical context and repertoire would not generally be associated with the tradition of taiko drumming. In fact, this broad class of Japanese percussion instruments is definitely not primarily used in musical compositions pertaining to the abovementioned genres and contexts. In that regard, Taiko no Tatsujin shows a crucial difference with comparable, music-oriented digital games, such as Guitar Hero (Harmonix 2005) or Rock Band (Harmonix 2007). The similarities between these games are primarily found in the game mechanics, which, at least on a basic level, require the players to correctly "hit" a pattern of notes in time with popular songs. However, both Guitar Hero and Rock Band feature musical compositions that are archetypical of the musical practices represented; as such, these digital games consistently aim to be legitimately positioned within a musical discourse, largely situated within the "rock" musical genre. Taiko no Tatsujin, instead, takes a more ironic, surreal approach, juxtaposing the relatively traditional practices of taiko drumming with musical compositions largely situated within the modern cultural sphere of the media mix.

Therefore, on one hand Taiko no Tatsujin entails the musical media literacy of its players, referencing previously available compositions situated in the media mix; on the other hand, a different kind of literacy is involved, situated outside of media literacy and within the cultural practices of taiko performances. 
How is it possible to describe the overall musical literacy conveyed by Taiko no Tatsujin? To answer this question, this paper will expand the context of musical literacy in digital games, going beyond media analysis, to include other forms of musical participation not based on media forms. In doing so, I argue that the musicological contextualization of digital games cannot be solely situated within a given mediascape (be it the Japanese one or otherwise), but rather can benefit from taking into account a diverse range of cultural practices. The musicological theoretical tools deployed in this paper will reflect this scope, referring to the concept of musicking introduced by New Zealand musicologist Christopher Small (1998). Small considers “music” not as a noun, but as a verb: "to music is to take part, in any capacity, in a musical performance, whether by performing, by listening, by rehearsing or practicing, by providing material for performance (what is called composing), or by dancing” $(1998,9)$.

Small specifies that this list of music is not finite, and does not exclude other possible musickings:

The verb to music is [...] descriptive, not prescriptive. It covers all participations in a musical performance, whether it takes place actively or passively, whether we like the way it happens or whether we do not, whether we consider it interesting or boring, constructive or destructive, sympathetic or antipathetic $(1998,9)$.

In this regard, this paper identifies the musicking enabled by Taiko no Tatsujin, and the complex web of musical meanings referenced by it.

\section{GEEMU ONGAKU FROM MEDIA MIX TO LUDO MIX}

In this section, I will introduce the concepts of media mix, ludo mix and geemu ongaku (or videogame music), positioning Taiko no Tatsujin within this specific cultural context. 
The term media mix was originally intended, within the Japanese mediascape, as a marketing strategy that targets different advertising media in an organic, comprehensive fashion. This understanding of media mix was formalized in 1963 by the ad journal Senden Kaigi (Advertising Meeting) (Steinberg 2012, 139). However, as mentioned, "media mix" now identifies a phenomenon of convergence between different media, in which given intellectual properties are spread across a number of different outlets such as manga, anime, toys and more. While the compatible idea of media convergence has already been described by Jenkins (2006), mostly in relation to the North American mediascape, Steinberg argues that the media mix phenomenon has, instead, a specific history situated in Japan, and is primarily centered on anime.

The emergence of Japanese television animation, or anime, in the 1960s as a system of interconnected media and commodity forms was $[\ldots]$ a major turning point and inspiration for [...] the media mix (2012, viii).

While synergy across media is an international phenomenon, Ito draws distinctions between the Japanese media mix and the US mediascape:

Unlike with US origin media, which tends to be dominated by home based media such as the home entertainment center and the PC Internet, Japanese media mixes tend to have a stronger presence in portable media formats such as Game Boys, mobile phones, trading cards and character merchandise that make the imagination manifest in diverse contexts and locations outside of the home $(2010,86)$.

Digital games are increasingly involved in the media mix, often taking a central role. Research has considered this relatively new phenomenon and its significance, identifying game-centered forms of media mix, sometimes called either "ludo mix" (Blom 2019; Bjarnason 2019; Chiapello 2019), “gameic media mix” (Steinberg 2015) or "geemu media mix" (Picard and Pelletier-Gagnon 2015), which I will refer to as ludo mix. These compatible definitions 
considered games as "central to the conceptualization and deployment of the media mix" (Steinberg 2015, 52). As noted by Steinberg (2012, 177-182; 2015), the ludo mix as a crossmedia marketing strategy has been pioneered by the Kadokawa Corporation with the Madara franchise, which includes digital games, manga and anime. Madara began in 1987 "not as a game, but rather as a manga that mimicked the properties and rules of a role-playing game” (Steinberg 2015, 45), banking on the coeval popularity of the RPG genre. Kadokawa would subsequently produce interconnected Madara media products, adopting a style of media mix where games exert a fundamental structuring role. More recently, Kadokawa produced the franchise .hack, "a multimedia series whose media instances [feature] manga, anime, Playstation 2 (PS2) console game” (Lamarre 2018, 289). .hack represents a mature example of ludo mix: Kadokawa has in fact carefully planned the release of its different iterations, "releasing the .hack manga in a Kadokawa magazine and broadcasting the anime series just before launching the first game” (Lamarre 2018, 293). Picard and Pelletier-Gagnon also focused on a gamecentered media mix, introducing the concept of "geemu media mix", aiming to analyze Japanese digital games (or geemu, in Japanese) in the media mix: "understanding the different articulations of the geemu media mix allows to better identify the development, marketing and consumption practices of video games in Japan” (Picard and Pelletier-Gagnon 2015). Given these examples, the ludo mix can be considered as an established phenomenon within the Japanese mediascape.

The role of digital game music has also been specifically analyzed in relation to the media mix. In their analysis of geemu ongaku, Yamakami and Barbosa identify in the 1980s the "golden age" of Japanese videogame music (2015). The authors primarily understand as geemu ongaku musical compositions originally composed for digital games. While they consider it difficult to formally define geemu ongaku as a consistent genre according to its intrinsic musical characteristics, they argue that, at least commercially, it can be considered as such, noting that by the end 
of the 1990s, over 350 CDs of "game music" were available on the Japanese market. Fritsch also documented the popularity of these releases (2016).

Specific magazines have also been instrumental in the development of geemu ongaku culture. Beep, founded in 1984 by Softbank, included not only "sonosheets"1 of game music, but also criticism and analysis of music or sound design, basic courses in acoustics, interviews with composers, and introductory guides to direct audio recording of video games in arcade centers (Yamakami and Barbosa 2015, 145). Geemu ongaku culture, however, does not appear solely in media forms such as music CDs, digital games, or magazines: the geemu ongaku repertoire is also performed during live concerts, which features diverse ensembles ranging from small bands to large symphonic orchestras. Live geemu ongaku concerts also facilitated the emergence of "sound teams": musical groups like Zuntata, Kukeiha Club, or Sega Sound Team Band (Figure 2). Teams, formerly hidden behind a game title or company name, came under the spotlight as true "musicians" and artists. The sound part of their games was recognized as a musical "work", and since that time, any new release, for many admirers, meant the creation of a new piece by their favorite musician (Yamakami and Barbosa 2015, 147). 


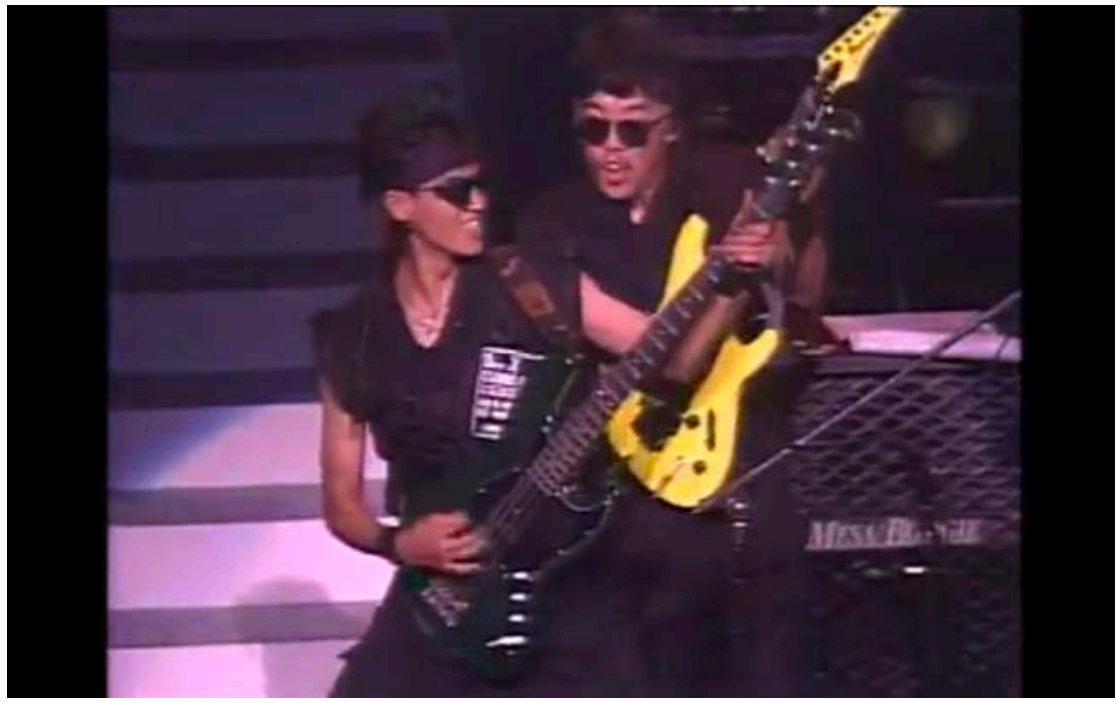

Figure 2: Members of the Sega Sound Team Band performing live. Still frame from Game Music Festival Live '90: Zuntata Vs. S.S.T. Band (1990). https://youtu.be/R_OPKOFBL8k

Taiko no Tatsujin participates in remediating geemu ongaku, since it features musical compositions from prominent digital game franchises. Starting from its 8th arcade version, Taiko no Tatsujin 8 (Bandai Namco 2006), geemu ongaku was featured as a distinct musical genre with its own dedicated playlist, alongside J-pop hits, anime songs, and other genres. A total of 12 geemu ongaku songs were included; tracks ranged from classic, easily recognizable tunes like the Super Mario Bros. (Nintendo 1985) and The Legend of Zelda (Nintendo 1986) respective main themes, to songs from the Bandai Namco franchises Tekken (Namco 1994) and Soulcalibur (Project Soul 1998). Also notable is the inclusion of the main theme of Darius (Taito 1989), a classic shoot 'em up arcade game. The remediation of geemu ongaku tracks in Taiko no Tatsujin also happens through collaboration and exchanges with other popular rhythm and music games. An example of this is the annual live event Tenkaichi Otogesai (literally “The Universe's Greatest Rhythm Game Festival”), which started in 2014 and 
features a rotating cast of arcade rhythm games by Sega, Taito, Konami and Namco (Figure 3), including Taiko no Tatsujin. The event is a unique combination of a gaming tournament and musical happening, and routinely sees tracks made popular by one game being featured in the other, celebrating geemu ongaku across different music games. For example, the track Got more raves?, made popular by the Taito rhythm game franchise Groove Coaster (Matrix Software 2011/2019), was included in Taiko no Tatsujin starting in 2015 as part of a ludo mix promotional strategy connected with Tenkaichi Otogesai. The track was composed and arranged by Koshio Irozaka, a former Zuntata team member, strengthening the connection of the featured games with geemu ongaku culture.

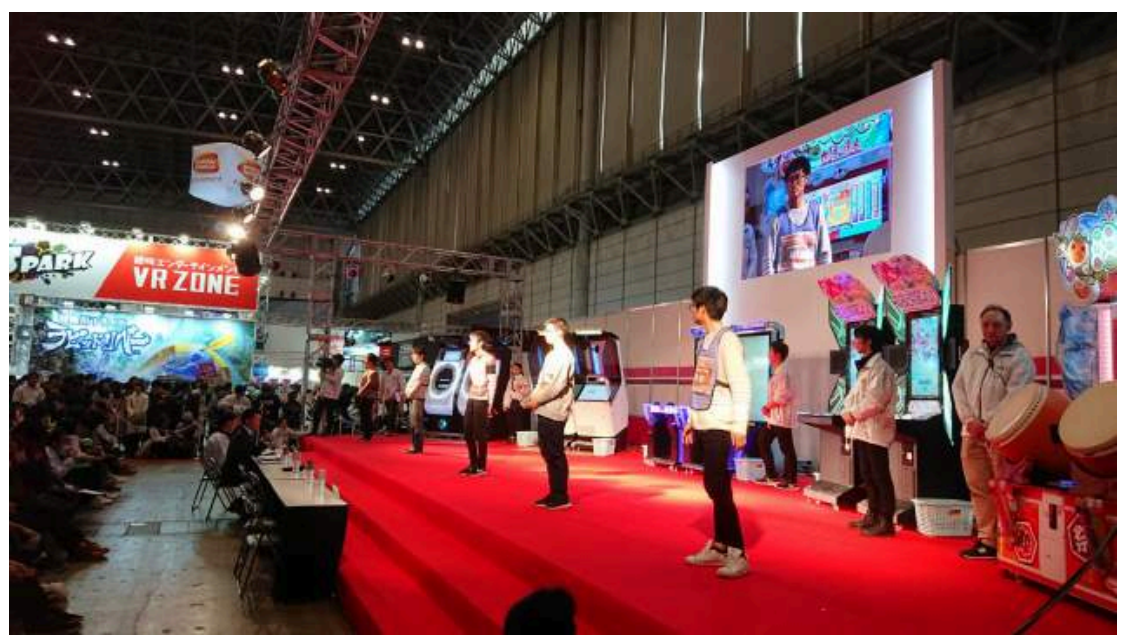

Figure 3: Players line up on stage at Tenkaichi Otogesai 2019, held at Makuhari Messe, Tokyo. https://twitter.com/AOU_Tenkatui/status/ 1089033903891931136/photo/1

However, Taiko no Tatsujin does not just remediate previously available geemu ongaku compositions, but also contributes to the genre's repertoire. In fact, the game regularly features several original compositions that should arguably be considered as part of geemu ongaku. These original tracks are grouped in the game song list under the moniker of "Namco Originals", and are specifically composed for Taiko no Tatsujin. Compatibly with what has been 
described by Yamakami and Barbosa with regards to other geemu ongaku tracks, the Namco Originals are introduced in a given digital game and subsequently remediated in different ways. For example, the audio CD Taiko no Tatsujin OST - Katanuki (2018) is a compilation consisting entirely of recent Namco Originals tracks. This latter audio CD is one of the many available records dedicated to Taiko no Tatsujin: these releases usually feature a mix of different genres, juxtaposing, for instance, anime songs and J-pop. The Katanuki compilation can therefore be considered as a testament to the popularity of Namco Originals within geemu ongaku culture, proving Taiko no Tatsujin's contribution to the genre's repertoire.

Taiko no Tatsujin is therefore embedded both in the media mix and in geemu ongaku culture, structuring a unique example of musically-oriented ludo mix. As illustrated, a variety of different forms of musical participation, or musickings, are practiced within this specific musical culture. Even a brief overview reveals that the different musickings performed by geemu ongaku participants range from playing given digital games, to purchasing geemu ongaku CDs, to buying dedicated magazines, and more.

\section{GAME MUSICAL LITERACY IN THE LUDO MIX}

The musical culture described by Yamakami and Barbosa documents the peculiarity of the musical literacy shared by geemu ongaku listeners. While I have previously introduced the different ways in which Taiko no Tatsujin engages with geemu ongaku, it will now be necessary to further debate the concept of musical literacy in order to understand how it applies to geemu ongaku and to Taiko no Tatsujin.

As previously mentioned, van Elferen (2016) has discussed musical literacy across media, defining it as the fluency in listening and interpreting "film, television or advertising music". The concept expands on previously formalized theoretical tools related to media and game studies, applying them specifically to music 
in digital games. Media literacy has been defined by Roepke as "habituated practices of media engagement shaped by cultural practices and discourses” (Roepke, 2011, as cited in van Elferen, 2016). Audiences have "developed a certain expectation curve with regards to [these media] form, style and possible sociocultural meanings" (van Elferen 2016) through engagement with any kind of medium, including digital games. While media literacy is not medium-specific, Zagal has applied the concept, focusing on digital games. The "ludoliteracy" of digital game players is the sum of diverse skills, ranging from the competence of operating a game console, to the ability in interpreting established game design tropes and situations (Zagal 2010).

Game musical literacy is therefore formalized as a combination of media and ludic literacy:

Combining the audiovisual literacies of film and television music with ludoliteracy, game soundtrack design appeals to a specific game musical literacy. Through intertextual references to audiovisual idioms from other media, game soundtracks deploy player literacy for their immersive effect: it is because gamers recognise certain composing styles that they are able to interpret gaming events and feel involved in gameplay, game worlds, and game plots. Boss fights, for instance, are often accompanied by the high-tempo, brass-heavy, dissonant orchestral scores with syncopated percussion that players recognise from exciting scenes in heroic action movies (van Elferen 2016).

This conceptualization of game musical literacy is therefore focused on interpretation of musical sections, cues or fragments during gameplay. Moreover, it also stresses the role of these musical parts, which contribute to the overall semiotic process happening during their subsequent deployment in any given gameplay situation. In other words, players also make sense of in-game situations, thanks to cross-media referencing. This point is also reiterated within the relevant literature: "Game music [...] establishes, utilizes and reinforces musical signifiers (interacting 
with a wider pan-media currency of musical semiotics)" (Summers 2016, 141).

The concept of game musical literacy, however, can also be expanded, for a productive application of the concept, to geemu ongaku in the media mix, including diverse forms of musical participation that are detached from direct engagement with digital games. In fact, the various different musickings, described in the previous section of this paper, showed the diverse forms of musicking available and practiced across geemu ongaku culture. Some of these musickings have little to do with actual gameplay or with games-as-played, so to speak. Rather, they seem to have formed a robust musical culture of their own, which finds, in the medium of digital games, a unifying territory. Geemu ongaku, in fact, consistently maintains its "game music" identity even when it is extrapolated from the digital game medium and transported in a different medium or setting.

Participation in geemu ongaku is not even necessarily primarily associated with actual game-playing. Exposure to the geemu ongaku repertoire is arguably connected with listening to music CDs or participation in live happenings just as much as it is related to playing digital games. Geemu ongaku, therefore, nonchalantly traverses not only different media (digital games, music CDs, magazines, etc.) but also exists in live concerts. This aspect is crucial, as it proves that geemu ongaku culture actually extends beyond the conventional confines of the media mix. Live happenings, in fact, are in general hardly identifiable as "media"; specifically, live concerts are not usually included in discussions regarding the media mix. In this case, musical participation in digital games is therefore not solely confined within a media-based environment.

The aspects debated within this section are arguably legitimately related with the "game musical literacy" of participants in geemu ongaku culture. The literate listener is in fact capable of discerning geemu ongaku, regardless of any formal characteristic of a given 
geemu ongaku composition. This is unlike other possible and apparently similar examples of "game music". Chip music or chiptune, for example, is a musical genre identifiable with digital games, and particularly focused on the 8-bit sound aesthetic. It is not easy to pin down the formal characteristics of the genre, as it "continues to spread into innumerable musical and media genres, niches and intertextuality", but it can be said that it is at least "semi-consistent in its microsound or 'bit-crushed' timbres" (Reid 2018, 280). In this sense, chiptune strives to establish a discourse of authenticity based on the timbric qualities of the hardware used to produce such compositions. Geemu ongaku, on the other hand, does not have coherent or at least recurrent structural components or characteristics. Only a literate music community can therefore uphold the confines of geemu ongaku, being able to apply the genre's tropes thanks to a deep web of interconnected semiotic meanings, which are made explicit during a variety of different musickings. In that regard, geemu ongaku participants do not just apply the audiovisual literacy that they acquired by watching film and television to "interpret gaming events and feel involved in the gameplay” (van Elferen 2016), but rather are engaged in a much wider musicking phenomenon. In that regard, Frith makes a compelling argument about the productiveness of musical activities conducted by listeners of popular music:

Different musical activities (listening, playing, performing, dancing) produce different aesthetic objects. In particular [...] the music produced by the composer must be distinguished from the music produced by the listener (with performers, critics, and analysts occupying uneasy positions between the two) (Frith 1996, 267).

And indeed, geemu ongaku is an excellent example of these kind of processes, confirming that "musical meaning is not inherent (however “ambiguously”) in the [musical] text” (Frith 1996, 250), but rather, it is constructed by the interplay of previously mentioned musickings practiced by geemu ongaku participants.

As mentioned, different iterations of Taiko no Tatsujin have featured a variety of geemu ongaku compositions, ranging from 
original recordings to new arrangements of popular tracks. Taiko no Tatsujin therefore remediates geemu ongaku in original fashion, effectively adding a new context for tracks that already belong to the genre. The game musical media literacy entailed by Taiko no Tatsujin can also be considered as a form of ludo mix musical literacy. In Taiko no Tatsujin, in fact, players experience specific musicking participation, drumming along with certain musical tracks on the taiko. However, this musicking also references other popular digital game compositions familiar to the players. Possibly, the players have in fact previously experienced such tracks when playing other digital games that exposed them to the same musical compositions remediated by Taiko no Tatsujin. This complex referencing system is inherently ludo-centric and situates the game in a specific semiotic domain, discernible by geemu ongaku participants, thanks to their game musical literacy; however, it does not necessarily have any functional, gameplayrelated implications. It provides valuable cultural context, but it does not indicate any gameplay scenario (such as a boss fight, as previously mentioned by van Elferen). In that regard, I maintain that digital game musical literacy is not necessarily functionaloriented, and it cannot be solely reduced to its applications during engagement with digital games.

\section{ON TAIKO DRUMMING}

In the previous section, I expanded the concept of game musical literacy, commenting on occurrences in which players refer to their literacy while not directly being involved in gameplay activities. I have also situated Taiko no Tatsujin within the ludo mix, the media mix, and geemu ongaku. That, however, is still not enough; the musical literacy referenced by Taiko no Tatsujin, in fact, expands far beyond the conventional confines of the ludo mix. I now intend to expand further on the overall musical literacy at stake with Taiko no Tatsujin by looking at the most evident musical reference set by the game: taiko drumming. The analysis of this aspect will shift focus from musical content and compositions to a variety 
of relevant forms of musical activities and participation forms. The subject matter of musical analysis of digital games, in fact, is not only constituted by the musical compositions contained in a given game example; rather, it can also include in the discussion the different musickings practiced by game players (Oliva, 2017, 2019a, 2019b, 2019c).

Taiko no Tatsujin is primarily based on taiko drumming; that is obviously the most self-explanatory musical connection established. In order to understand what kind of musical literacy is being referenced in this case, it will however be necessary to introduce taiko drumming. What is a taiko drum, and what are the musical and cultural practices connected to it? A fully detailed answer to this question would expand well beyond the limits of this paper; nonetheless, a general introduction to the meanings of taiko practice is necessary to appreciate the musical participation made possible by Taiko no Tatsujin.

In general, a taiko is a wooden, barrel-shaped drum. It can be used as the centerpiece for various kinds of musical performances, involving one or more taikos of different sizes, alongside different musical instruments such as flutes, shamisens, as well as vocal and dance performances. Taiko's history and developments are rich and varied, having passed through different eras and cultural contexts.

Taiko is an instrument that historically has been used in Japanese classical music such as Gagaku (lit., "elegant” or "refined," the Imperial court music of Japan dating back to the sixth century) and folk and religious music, as in traditional festivals tied to Buddhism and to Shintoism. The drum was either a solo instrument or played in relation to other musical instruments and characterized by a fixed form and steady, predictable rhythm with little syncopation (e.g., unexpected stresses of rhythmic beat) (Powell 2012, 104).

This historical form of taiko practice underwent a considerable transformative phase after World War II. 
Although the roots of wadaiko [literally "Japanese drum", a term here used interchangeably with "taiko"] music may be traced to the drum and flute ensembles that accompanied Shinto rituals, agricultural rites, and Bon festivals in Japan for centuries, wadaiko has come to mean a new drumming style that developed after World War II out of the music played by such ensembles [...]. Groups started performing at hot spring spas and hotels as tourist attractions in the mid-1950s. The performances of a few such groups at the 1964 Olympic Games in Tokyo and the 1970 World Exposition in Osaka placed wadaiko music in the national limelight (Terada 2001, 37-38).

Banking on their increasingly national popularity, taiko events have, in recent years, extended to international venues. Formed in 1981, Kodo is arguably the most prominent and well-known taiko ensemble to ever operate. In the same year of its formation, Kodo made its international debut, performing in Berlin and touring Italy, West Germany and Japan (Kodo, 2015). This milestone can be considered as the start of the contemporary international popularity of taiko performances. Following this event, taiko exhibitions have been staged at the Nagano Winter Olympics in 1998 and at the FIFA World Cup, which was co-hosted by Korea and Japan in 2002 (Bender 2012, 3). Taiko no Tatsujin seems to be regarded as proof of the popularity of taiko performances:

Building on this popular appeal, [taiko] has even been converted into a video game. In "Taiko no Tatsujin", an arcade game created by the Japanese company Namco, players use wooden mallets to tap [...] on an electronic drum shaped like a taiko. The company has released software and hardware home console versions of "Taiko Master", along the line of the "Guitar Hero" and "Rock Band" series of video games. Clearly popular domestically, taiko drumming has arguably become Japan's most globally successful performing art (Bender, 2012, 4).

The previous quote is interesting for at least a couple of reasons. To start with, notice how being the subject of a digital game is read by the author as a testament to the popularity of a certain phenomenon. Gone are the days in which a digital game could be superficially dismissed as an automatic trivialization or belittling 
of certain cultural aspects. But apart from considerations related to the cultural status awarded to the medium of digital games in this context, more questions arise. In his overall analysis, Bender does not focus on the compositions being played (the musical scores that taiko players would eventually perform). Rather, taiko practice is considered from the ground up in his analysis, as a performing art: a perspective that necessarily includes various aspects of anthropological value. Specifically, taiko practice is understood as a form of "new folk performing art", a definition that intends to "centre attention on performance culture that is presumed to be a communal possession, expressive of that community, transmitted orally within it, managed by it, and owned by no one of the community members more than another" (Bender 2012, 11). The horizontal perspective traced by this definition seems to be typical of informal musical setups, differing from musical forms that are structured in a more vertical or hierarchical fashion. The latter structures are best exemplified by the clearcut roles established within Western classical music practice, as mentioned and critically addressed by Small, who details the emergence of the conductor role within orchestral ensembles as the person "in charge of every detail of the performance" $(1998,83)$.

More generally, the new folk performing art is, however, an expression form ascribable to non-notated musical traditions. The latter is a crucial notion: Small's criticism of musicological practice is in fact based on the discipline's focus on notated music, and its neglect of performance-based, non-notated musical forms. "Musicology is, almost by definition, concerned with Western classical music, while other musics, including even Westerns popular musics, are dealt under the rubric of ethnomusicology" (Small, 1998, p. 3). Similar concerns have prominently been raised by Cook, who notes that "musicologists have traditionally treated music as a form of sounded writing” (2014, 1), even if "it is performers who function as the primary motors of musical culture" (2014, 25), provocatively adding that "composers, after all, just write the notes” (2014, 25). Abbate, touching on similar points, adds that "musicology [...] generally bypasses performance, 
seeking meanings or formal designs in the immortal musical work itself” (2004, 505). This creates a methodological conundrum: musicology claims to study music, but continuously refers to "music" as only a segment of musical expression. The problematic consequences are that "the word music becomes equated with works of music in the Western tradition" (Small, 1998, p. 3). Ethnomusicology, "a [...] word which is widely used to refer to the study of the different musical systems of the world” (Blacking 1973, 3), is faced with the complex task of studying a plethora of musical systems, which are intertwined with countless practices, histories and, in general, cultural implications of any possible human group. Bender's research is therefore compatible with this theoretical frame, adopting a wide ethnomusicological lens in order to pin down musical characteristics of taiko culture. Once again, the complexity of taiko performance culture is a large subject, but I intend to extrapolate from Bender's work those meanings that will be useful for a proper musical analysis of Taiko no Tatsujin. In fact, musicking with Taiko no Tatsujin also involves engaging with musical practices that go beyond the limits of musicology described by Small. The next section will discuss the musical literacy at stake in Taiko no Tatsujin.

\section{TAIKO NO TATSUJIN AND MUSICAL LITERACY}

The actual taiko instrument is only one of the many facets of taiko culture, which, as discussed, is a vast topic with deep ramifications in Japanese culture. Similarly, the musical literacy to be discussed involves comparably vast implications.

The taiko featured in Taiko no Tatsujin is most probably a reference to the chü-daiko (also called miya-daiko): "the most extensively used variety of taiko in the contemporary taiko ensembles" (Bender 2012, 32). The chü-daiko is in fact often mounted on a slanted stand (josuki-daiko) (Vetter 2015) that tilts the drum, favoring a comfortable position for the performer. This 


\section{Costantino Oliva}

setup is similar to the standard arcade iteration of Taiko no Tatsujin (Figure 4).

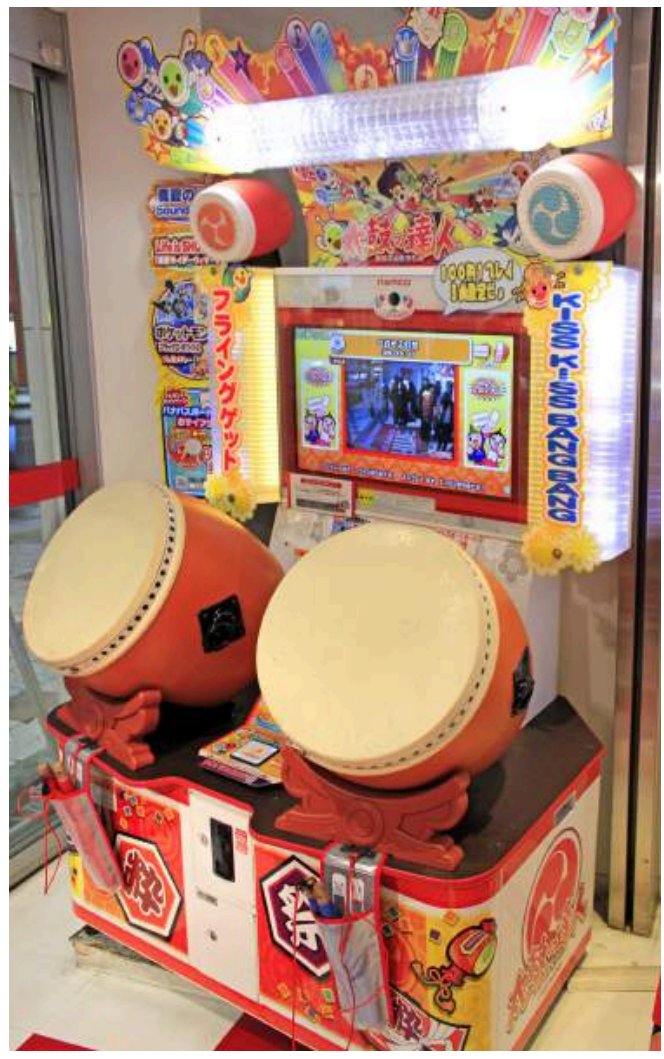

Figure 4: A Taiko no Tatsujin 2011 (Bandai Namco 2011) arcade cabinet. Picture by Minseong Kim, CC BY-SA 4.0.

The chü-daiko is used in religious rituals and in the folk performing art genre. In Taiko no Tatsujin, as mentioned, there is no direct reference to religion, and the emphasis is arguably put in representing the largely secular contemporary matsuri. Also, the chü-daiko is not a type of taiko used in classical stage performing art, thus excluding that specific musical culture from the referencing system conveyed. 
The game does not directly or literally refer to the taiko techniques associated with chü-daiko either. However, through the design of its input devices, Taiko no Tatsujin encourages gestures that are comparable to the typical techniques associated with playing a large taiko, which is considered an intense physical performance, requiring strength and stamina. This rhetoric of physical strength in taiko performance can be traced back to the performance piece, Õdaiko, created by the taiko group Ondekoza.

In Õdaiko (literally, “big drum”), a drummer, usually a man, stands naked except for a white loincloth and headband in front of an enormous drum. Slowly and dramatically, the drummer draws together his large bachi (wooden drum mallets) and begins to pound furiously on the instrument for more than ten minutes [...]. Since its creation by Ondekoza, Õdaiko has been modified into a generic style of performance by countless amateur and professional taiko groups both within and beyond Japan [...]. However, the focus on one drummer pounding ferociously on a large drum is consistently maintained, emphasizing the tremendous effort it takes to perform with strength and skill on such an imposing instrument (Bender 2010, 844, 863).

This aspect of taiko performance epitomized by Õdaiko is present in Taiko no Tatsujin, particularly considering its arcade iterations. In fact, the big plastic drums that form an integral part of the arcade cabinet are calibrated to register input only if struck considerably hard, and will not detect a soft touch. This design choice renders the execution of rapid note sequences considerably difficult, as each drum strike needs to be loud and emphatic. The timbre of the taiko, exemplified by its characteristic deep thud, is also prominently featured, alongside the highly pitched rim shot. As the game mechanics guide the player towards hitting either the center or the rim of the drum, the resulting acoustic output will be double. While the plastic taiko itself provides organic, direct acoustic feedback after being struck, it also triggers digital sounds reproduced by the cabinet speakers: the subsequent acoustic feedback is a combination of recorded and "live" sounds. The resulting, typical Taiko no Tatsujin performance has the potential 
to induce players to "pound ferociously", as Bender mentioned; but other evident references related with the performance practice and repertoire of prominent taiko groups such as Kodo or Ondekoza are virtually absent.

Primarily, in fact, Taiko no Tatsujin does not center its range of references on the taiko drum as an instrument and its use in performance art settings, but rather focuses on certain elements that are typical of its adoption within festive contexts. While I have previously situated Taiko no Tatsujin in the ludo mix, I now intend to position it within the larger frame of the contemporary, shifting meanings surrounding Japanese festivals, or matsuri. According to Bender, "the common English translation of the Japanese matsuri as "festival" lacks the nuance of the Japanese term" $(2012,106)$. The key difference lies in the religious nature of the term. Even if sometimes used to indicate a religious festivity, the common use of the English term "festival" can, of course, indicate a secular happening, perhaps a large open event. In Japanese, instead, the original meaning of "matsuri" was strictly religious. In recent times, however, the term has started to be used to also indicate secularized events, incorporating the meanings of the English term. This shift is particularly common within urban matsuri, such as those taking places in the large metropolitan areas of cities like Tokyo or Osaka. Contemporary taiko groups seem to increasingly "base membership on residence, regardless [...] of shrine affiliation" (Bender, 2012, p. 108). The communal aspect is therefore still strong, but shrine affiliation is no longer a fundamental discriminating factor. To corroborate these points, I can anecdotally mention to have had the opportunity to participate in one of such festival, the Akasaka Jodoji Bon Odori in July 2016, held in the ward of Minato, Tokyo. Bon Odori, which translates to Bon dance, is a style of dancing performed during the summer Obon period. Appropriately, a large taiko drum took center stage on that occasion. Alternating performers would share the instrument, playing a repertoire of pre-recorded musical tracks, sometimes accompanied by crotal bells. The event explicitly invites people external to the neighboring community to 
participate. Members of the organization would offer free light drinks to tourists, and invite them to join the bon odori dance.

Through visual elements, Taiko no Tatsujin sets up a playful matsuri of its own, complete with food stalls, goldfish scooping, and of course the classic tower (or yagura) bandstand, a centerpiece of the matsuri. The tower is prominently featured on the cover and promotional material of the Drum Session! (Bandai Namco 2017) iteration of the franchise (Figure 5a), and also appears on the menus and in certain stages of the game itself (Figure 5b).

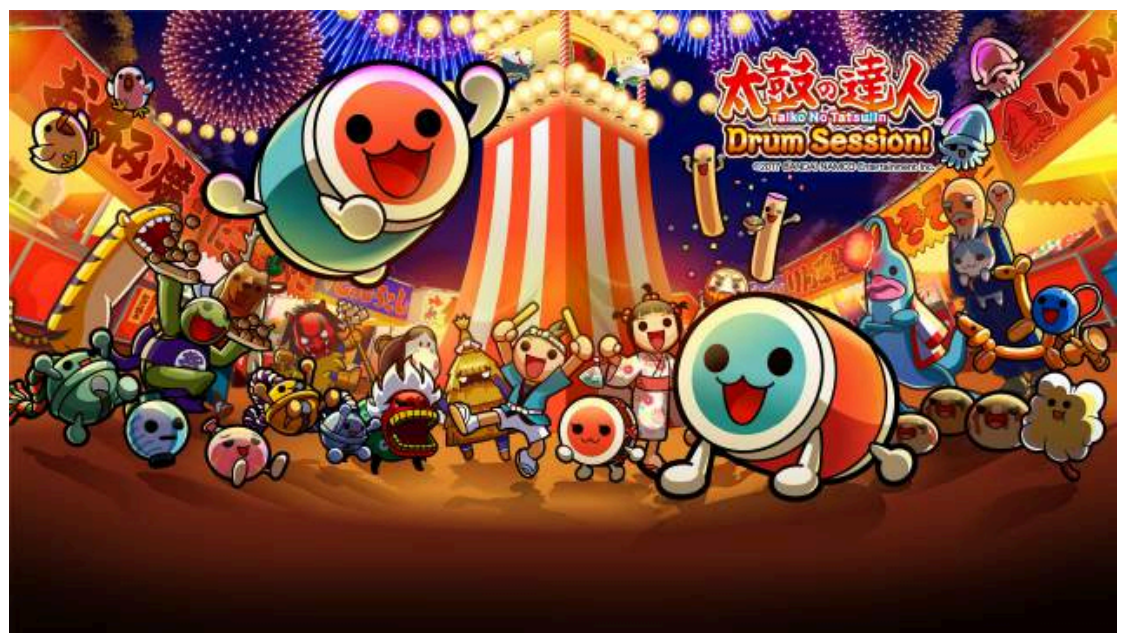

Figure 5a: Promotional image for Taiko no Tatsujin: Drum Session! (Bandai Namco 2017). A yagura bandstand is displayed in the center of the picture. 


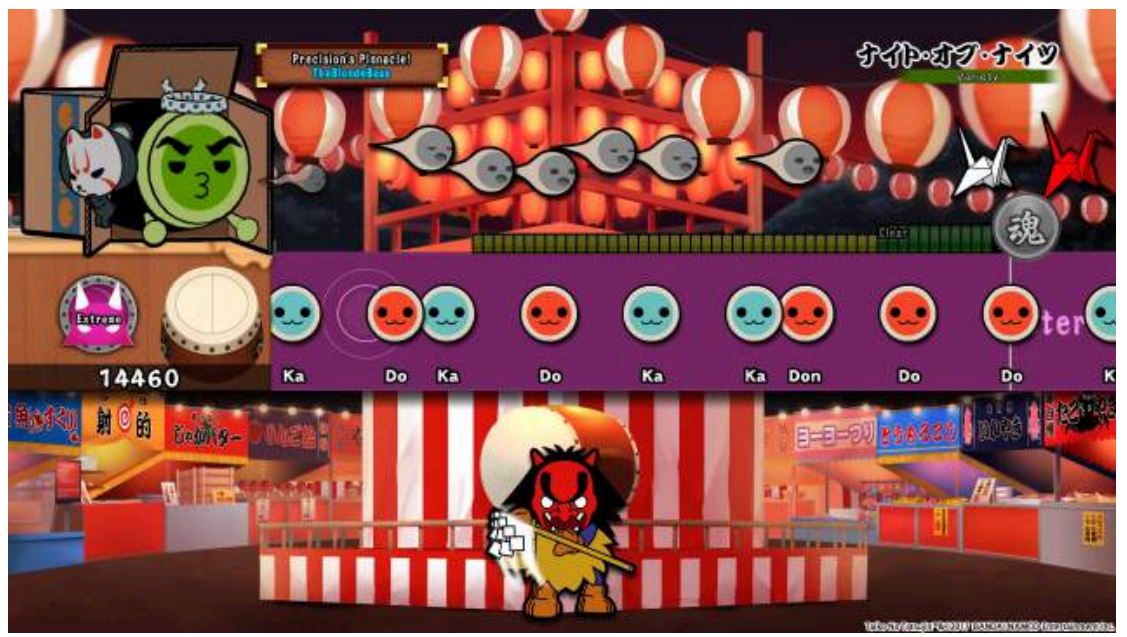

Figure 5b: Promotional image for Taiko no Tatsujin: Drum Session! (Bandai Namco 2017). Yagura bandstand and food stalls are depicted in the background.

This range of references, while not directly or solely musical, is nonetheless imbued with musicking value; as such, in this context they can be considered as part of the musical media literacy conveyed by the game. Arguably, players without such musical literacy will be unable to competently place the collective imaginary projected by Taiko no Tatsujin in an appropriate semiotic domain, thus missing on a variety of referenced musicking meanings. Moreover, in this case, the game musical literacy does not refer to exposure to other media, or even competence in the repertoire of a given musical genre. Rather, the literate player will be able to gather the larger musicking and cultural context associated with the taiko drum, thanks to the presence of a plastic replica of the instrument, and from a range of in-game visual elements portraying a typical matsuri scenario. As discussed, the musical compositions included in Taiko no Tatsujin have largely very little to do with taiko practice or matsuri, since they are instead situated in the cultural sphere of the media mix. 


\section{CONCLUSIONS}

This paper has debated Taiko no Tatsujin and the musical literacy it conveys. The concept was originally intended to emphasize the fact that digital game players are able to gather "intertextual references to audiovisual idioms from other media [...] to interpret gaming events and feel involved in gameplay, game worlds, and game plots" (van Elferen 2016). However, Taiko no Tatsujin involves a wider musical literacy, extending its referencing frame beyond the confines of media, to include musical meanings practiced within taiko drum culture. Moreover, Taiko no Tatsujin effectively works on two largely separated cultural paths: the media mix on one side, and taiko practice on the other, generating a unique, musical-centered ludo mix.

The first path is found by analyzing the musical content (here intended as the included musical compositions) of the digital game. The featured tracks are primarily imported from popular anime franchises, vocaloid singers, and pop and rock genres, as well as geemu ongaku. As such, it can be said to participate in musical media literacy in a conventional sense, as it refers to previous musical experiences from other media. However, as mentioned, Taiko no Tatsujin also participates in geemu ongaku, here understood as a loosely defined musical genre unified by digital games culture, in which game musical literacy is involved in different ways. The participants' musical literacy is also necessary during happenings that do not include direct engagement with digital games, such as listening to geemu ongaku music CDs or participating in live concerts. Nonetheless, participation in this musical culture involves a high degree of competence in game musical literacy. Players that do not fluently navigate this crux of musical references would of course still be able to go through Taiko no Tatsujin and engage with its game mechanics, but they would be unable to appreciate the creative juxtapositions of this unique example of ludo mix. 
The second path is found by analyzing the taiko musicking practices referenced by Taiko no Tatsujin. While the musical content of the game is largely based in the media mix, its primary musical inspiration is instead the taiko drum, and the complex web of meanings that taiko drum practice conveys. Taiko musicking is a case of contemporary oral tradition, rapidly evolving in the wake of new phenomena surrounding its practice. The musicking afforded by Taiko no Tatsujin can be situated in the cultural discourse that I have so far introduced. Devoid of religious implications, the game joyfully celebrates in exuberant fashion matsuri and taiko, juxtaposing them with meanings derived from a mishmash of media mix music. In doing so, the game actually creates a ludo mix that is composed of a mixture of musicking practices, generating an ironic, caricaturistic effect. The game, in fact, constitutes a case of music-focused digital game that prominently features musical practices based on non-notated music and its oral traditions. In that regard, it creates its credibility, not necessarily by featuring clearly recognizable musical compositions ascribable to a specific genre (like the comparable Guitar Hero and Rock Band franchises), but rather by conveying the larger musicking frame associated with taiko culture. These aspects, however, are not peripheral to taiko practice: rather, they could be considered its core.

This paper argues that analyses of musical literacy in digital games should therefore not be limited to musical content across media, but should rather involve the many different musicking practices that might be intertwined with digital games culture. Musicking, understood as any form of participation to musical performances (Small 1998), provides a meaningful theoretical frame where digital games can be situated (Oliva 2019).

\section{BIBLIOGRAPHY}

Abbate, Carolyn. 2004. “Music-Drastic or Gnostic?” Critical Inquiry (The University of Chicago Press ) 30 (3): pp. 505-536. 
Bandai Namco. Taiko no Tatsujin (franchise ) [Advanced Pico Beena, Android, Arcade, iOS, Nintendo 3DS, Nintendo DS, Nintendo Switch, Nintendo Wii, Nintendo Wii U, PlayStation 2, PlayStation 4, PlayStation Portable, PlayStation Vita]. Bandai Namco, Asia/North America/Europe, 2001/2018.

Bandai Namco. Taiko no Tatsujin: Drum Session! [Playstation 4]. Bandai Namco, North America/Europe, 2018. Played November, 2018.

Bandai Namco. Taiko no Tatsujin 2011 [Arcade]. Bandai Namco, Japan, 2011.

Bandai Namco. Taiko no Tatsujin 8 [Arcade]. Bandai Namco, Japan, 2006.

Bender, Shawn. "Drumming from Screen to Stage: Ondekoza's "Ōdaiko" and the Reimaging of Japanese Taiko." The Journal of Asian Studies 69 (3): 843-867, 2010

Bender, Shawn. Taiko Boom: Japanese Drumming in Place and Motion. University of California Press, 2012.

Bjarnason, Nökkvi Jarl. “A Recipe for Disaster? The Emerging Ludo Mix and the Outsourcing of Narrative.” DiGRA 2019: Game, Play and the Emerging Ludo Mix. Kyoto.

Blacking, John. How Musical Is Man? University of Washington Press, 1973.

Blom, Joleen.. “A Ludo Mix Perspective on Dynamic Game Characters.” DiGRA 2019: Game, Play and the Emerging Ludo Mix. Kyoto.

Chiapello, Laureline. "Ludo Mix as an Aesthetic Experience: Designing Games for Franchises.” DiGRA 2019: Game, Play and the Emerging Ludo Mix. Kyoto. 
Fritsch, Melanie. "Big in Japan. Digging in the History of Japanese Game Music Culture.” Ludomusicology Conference 2016, University of Southampton, UK.

Harmonix. Guitar Hero [Playstation 2]. Red Octane, North America/Europe/Australia, 2005. Played December 2006.

Harmonix. Rock Band [Xbox 360, PlayStation 2, PlayStation 3, Nintendo Wii]. MTV Games, North America/Europe/Australia, 2007. Played December 2008.

Ito, Mizuko. "Mobilizing the Imagination in Everyday Play: The Case of Japanese Media Mixes.” In Mashup Cultures, edited by Sonvilla-Weiss S., 79-97. Vienna: Springer, 2010.

Jenkins, Henry. Convergence Culture: Where Old and New Media Collide. NYU Press, 2006.

Kodo. Kodo History. Accessed March 10th, 2017. http://www.kodo.or.jp/general/history_en.html.

Lamarre, Thomas. The Anime Ecology: A Genealogy of Television, Animation, and Game Media. University of Minnesota Press, 2018.

Matrix Software. Groove Coaster [íOS, Android, Arcade, Nintendo Switch]. Taito. 2011/2019.

Namco. Taiko Drum Master [Playstation 2]. Namco, Japan/North America, 2004.

Namco. Tekken [Arcade, Playstation]. Namco, Japan/Europe/ North America, 1994. Played February 1996.

Nintendo. Super Mario Bros. [Nintendo Entertainment System]. Nintendo, Japan/North America/Europe, 1985. Played May 1991. 
Nintendo. The Legend of Zelda. [Nintendo Entertainment System]. Nintendo, Japan/North America/Europe, 1986. Played May 1991.

Oliva, Costantino. "Ergodic Musicking." Ludomusicology Conference 2019, Leeds, UK, 2019a.

Oliva, Costantino. Musicking with Digital Games $[\mathrm{PhD}$ dissertation]. Msida: University of Malta, 2019b.

Oliva, Costantino. “Musicking with Digital Games.” DiGRA 2019: Game, Play and the Emerging Ludo Mix, Kyoto. 2019c.

Oliva, Costantino. "On the Ontological Status of Musical Actions in Digital Games." 11th International Philosophy of Computer Games Conference, Krakow, 2017.

Picard, Martin, and Jérémie Pelletier-Gagnon. "Geemu and media mix: Theoretical approaches to Japanese video games :" Kinephanos - Journal of Media Studies and Popular Culture 1-19, 2015.

Powell, Kimberly A. "Composing Sound Identity in Taiko Drumming.” Anthropology \& Education Quarterly 101-119, 2012.

Project Soul. Soulcalibur [Arcade, Dreamcast, iOS, Xbox 360, Android]. Namco Bandai Games, Japan/North America/Europe, 1998. Played March 2003.

Reid, George. "Chiptune: The Ludomusical Shaping of Identity." The Computer Games Journal 7 (4): 279-290, 2018.

Roepke, Martina. "Changing Literacies: a Research Platform at Utrecht University.” Accessed January 16th, 2019. https://mmroepke.files.wordpress.com/2010/03/cl-workingpaper-1-voor-boekje.docx. 2011.

Small, Christopher. Musicking: the Meaning of Performing and Listening. Wesleyan University Press. 1998. 
Steinberg, Marc. "8-Bit Manga: Kadokawa’s Madara, or, The Gameic Media Mix.” Kinephanos 40-52. 2015.

Steinberg, Marc. Anime's Media Mix: Franchising Toys and Characters in Japan. University of Minnesota Press, 2012.

Summers, Tim. Understanding Video Game Music. Cambridge University Press, 2016.

Taito. Darius 2 [Arcade]. Taito, Japan, 1989.

Terada, Yoshitaka. "Shifting Identities of Taiko Music in North America.” Senri Ethnological Reports 22: 37-59, 2001.

van Elferen, Isabella. “Analysing Game Musical Immersion: The ALI Model.” In Ludomusicology : approaches to video game music, edited by Michiel Kamp, Tim Summers and Mark Sweeney. Equinox Publishing, 2016.

Various Artists [Audio CD]. Taiko no Tatsujin OST - Katanuki. Namco Bandai, 2018.

Vetter, Roger. "Nagado-daiko.” Grinnell College Musical Instrument Collection. 5 12. Accessed January 12th, 2019. https://omeka1.grinnell.edu/MusicalInstruments/items/show/149. 2015.

Yamakami, Yôhei, and Mathieu Barbosa. "Formation et développement des cultures autour de la "Geemu ongaku » (1980-1990)." Kinephanos - Journal of Media Studies and Popular Culture 142-160, 2015.

Zagal, José. Ludoliteracy: Defining, Understanding, and Supporting Games Education. ETC Press, 2010.

Zuntata and S.S.T. Band [VHS]. Game Music Festival Live '90: Zuntata Vs. S.S.T. Band. Pony Canyon, 1990. 